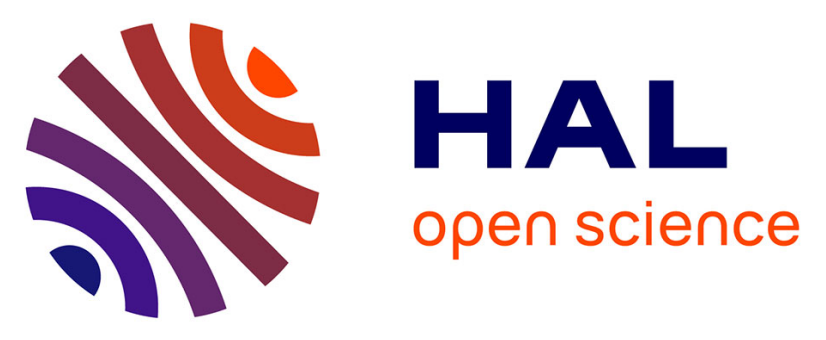

\title{
Resonant MEMS for Gas Detection Based on the Measurements of Physical Properties of Gas Mixtures
}

Isabelle Dufour, Luis Iglesias Hernandez, Priyadarshini Shanmugam, Jean-François Michaud, Daniel Alquier, Dominique Certon, Maria Dolores Manrique-Juarez, Thierry Leichle, Fabrice Mathieu, Laurent Mazenq, et al.

\section{- To cite this version:}

Isabelle Dufour, Luis Iglesias Hernandez, Priyadarshini Shanmugam, Jean-François Michaud, Daniel Alquier, et al.. Resonant MEMS for Gas Detection Based on the Measurements of Physical Properties of Gas Mixtures. 2020 Joint Conference of the IEEE International Frequency Control Symposium and the IEEE International Symposium on Applications of Ferroelectrics, Jul 2020, Keystone (virtual conference), United States. pp.1-3, 10.1109/IFCS-ISAF41089.2020.9234908 . hal-02481928

\section{HAL Id: hal-02481928 \\ https://hal.science/hal-02481928}

Submitted on 14 Dec 2020

HAL is a multi-disciplinary open access archive for the deposit and dissemination of scientific research documents, whether they are published or not. The documents may come from teaching and research institutions in France or abroad, or from public or private research centers.
L'archive ouverte pluridisciplinaire HAL, est destinée au dépôt et à la diffusion de documents scientifiques de niveau recherche, publiés ou non, émanant des établissements d'enseignement et de recherche français ou étrangers, des laboratoires publics ou privés. 


\title{
Resonant MEMS for Gas Detection Based on the Measurements of Physical Properties of Gas Mixtures
}

\author{
(Invited Talk)
}

\author{
Isabelle Dufour, Luis Iglesias Hernandez \\ Université de Bordeaux \\ Laboratoire IMS UMR-CNRS 5218 \\ Talence, France \\ isabelle.dufour@ims-bordeaux.fr
}

\author{
Priyadarshini Shanmugam, Jean-François Michaud, \\ Daniel Alquier, Dominique Certon \\ Université de Tours \\ GREMAN UMR-CNRS 7347 \\ Tours, France
}

\author{
Maria-Dolores Manrique-Juarez, Thierry Leïchlé, Fabrice Mathieu, Laurent Mazenq, Liviu Nicu \\ CNRS-LAAS \\ Toulouse, France
}

\begin{abstract}
Principles of gas detection using either resonant microcantilevers or CMUTs without sensitive coating are presented. The different principles which have been tested for hydrogen detection are based on the use of electrical measurements to estimate physical gas properties (mass density, viscosity, sound velocity).
\end{abstract}

Keywords-resonant MEMS; CMUT; microcantilever; gas detection; resonant frequency; quality factor; time of flight; viscosity; mass density; sound velocity

\section{INTRODUCTION}

The presented results are part of the H2MEMS project which is dedicated to the monitoring of radioactive waste repository, especially for hydrogen measurement. Due to the hostility of the environment within the targeted application, the gas sensors have to be not only sensitive, but mostly reliable and durable. Selectivity is not a concern and it is not a major specification because only hydrogen concentration may change significantly in this environment.

The principle adopted in the framework of this project is based on the measurement of physical properties of the surrounding gas (measurements of mass density, viscosity or sound velocity) using resonant MEMS (microcantilever or capacitive micromachined ultrasonic transducer, CMUT). All the proposed principles require no chemical sensitive layer. The absence of the sensitive coating, which is subjected to sorption or redox phenomena in classical chemical sensors, leads to a more reliable and reversible behavior. However, the absence of selectivity, which is usually inherent to the presence of a sensitive coating, can be compensated by combining multiple physical properties measurements as it will be presented.

\section{METHODS/RESULTS}

As stated in the introduction, two kinds of resonant MEMS have been used in this project:
- Silicon microcantilevers with electromagnetic actuation and piezoresistive readout. The details of the manufacturing process based on bulk micromachining using SOI wafer can be found in [1]. The dimensions of the microcantilever used for the presented results are: $1 \mathrm{~mm} \times 1 \mathrm{~mm} \times 10 \mu \mathrm{m}$.

- Silicon nitride capacitive micromachined ultrasonic transducers (CMUT). The fabrication process based on surface micromachining can be found in [2]. The dimensions of each membrane of the CMUT used for the presented results are: $32 \mu \mathrm{m} \times 32 \mu \mathrm{m} \times 450 \mathrm{~nm}$. Each CMUT is composed of thousands of membranes (the size of the chip is $8 \mathrm{~mm} \times 1 \mathrm{~mm}$ ).

In the case of the use of microcantilevers, the presented results are based on the measurement of both the resonant frequency and the quality factor, which allows to estimate simultaneously both the gas mass density and the gas viscosity [3]. An example of measurements obtained with different gases and the associated mass density and viscosity estimations are presented in Fig. 1.

In the case of the use of CMUT, the presented results are based on two different principles:

- The spectrum measurement of the impedance of the device is used, and based on an analytical modeling it has been proven that the measurement of the modulus of the admittance at the admittance anti-resonance is more sensitive than the one at resonance and much more sensitive than the measurement of the frequency either at resonance or anti-resonance. This theoretical result has been confirmed by measurements (Fig. 2).

- The measurement of time of flight which depends on the sound velocity in the gas allows gas detection. The measurement of time of flight has been done using 2 face to face CMUTs and different methods: in the time domain with impulse as actuation [4] (Fig. 3) or in the

This research was conducted thanks to the contest Programme d'Investissements d'Avenir of the French Government under the supervision of the French National Radioactive Waste Management Agency (ANDRA). 
spectrum domain by phase slope measurement [5] (Fig. 4).

\section{CONCLUSIONS}

In this two-pages abstract both the principles and examples of gas detection have been presented. In the invited talk more details will be given: sensitivity of the sensors, theoretical and measured limit of detection, example of the use of such non selective measurements to discriminate different binary mixtures.

Fig. 1. Resonant frequency measurements (top left) and quality factor measurements (top right) of silicon microcantilever for different gas mixtures $\left(\mathrm{H}_{2}, \mathrm{He}, \mathrm{CO}_{2}\right.$ and $\mathrm{CH}_{4}$ in $\left.\mathrm{N}_{2}\right)$ at different concentrations $(5 \%, 4 \%, 3 \%)$. Mass density (bottom left) and viscosity (bottom right) computed using these measurements.
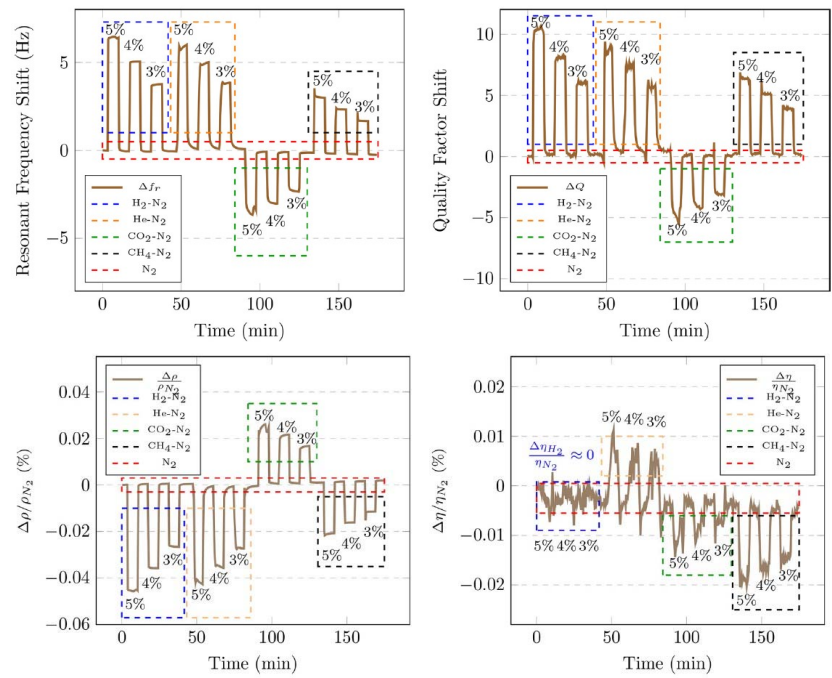

Fig. 2. Relative variation of different parameters extracted from the spectrum measurement of the admittance of CMUT during gas detection $\left(80 \%\right.$ of $\mathrm{CO}_{2}$ in $\mathrm{N}_{2}$ is used in order to better see the difference in the different parameters): Admittance at resonance $\left(Y_{\max }\right)$ or anti-resonance $\left(Y_{\min }\right)$, normalized frequency at resonance $\left(x_{r}\right)$ or at anti-resonance $\left(x_{a}\right)$.

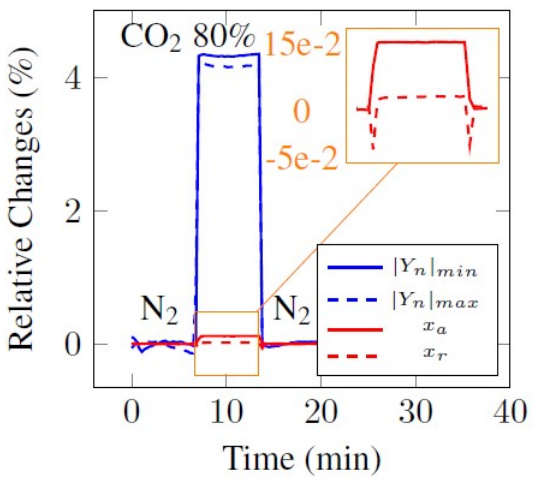

Fig. 3. Septup for the time of flight measurement in the time domain using two CMUTs (top). Time of flight measurement (bottom) during gas detection $\left(\mathrm{H}_{2}\right.$ in $\mathrm{N}_{2}$ ) at different concentrations $(5 \%, 4 \%, 3 \%, 2 \%)$.
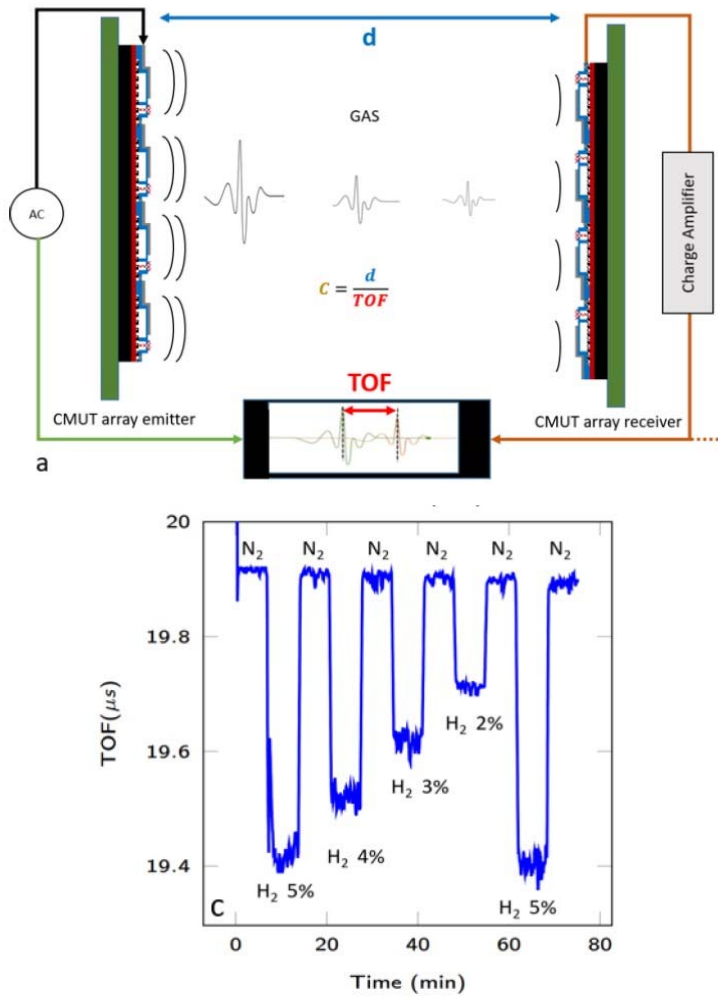

Fig. 4. Septup for the time of flight measurement in the frequency domain using two CMUTs (top). Time of flight measurement during gas detection $\mathrm{H}_{2}$ in $\mathrm{N}_{2}$ ) at different concentrations $(4 \%, 3 \%, 2 \%, 1 \%)$.
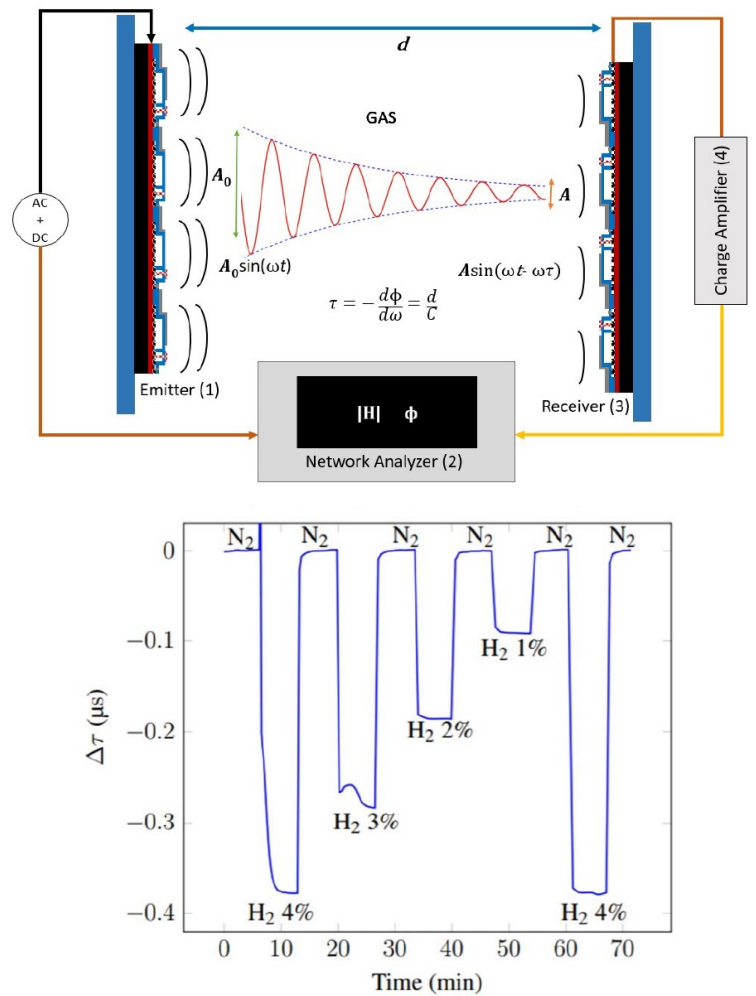


\section{REFERENCES}

[1] M.T. Boudjiet, J. Bertrand, F. Mathieu, L. Nicu, L. Mazenq, T. Leïchlé, S.M. Heinrich, C. Pellet; I. Dufour, "Geometry optimization of uncoated silicon microcantilever-based gas density sensors," Sensors and Actuators B, Vol. 208, 2015, pp. 600-607.

[2] J. Heller, A. Boulme, D. Alquier, S. Ngo, D. Certon, "Performance Evaluation of CMUT-Based Ultrasonic Transformers for Galvanic Isolation," IEEE Transactions on Ultrasonics, Ferroelectrics, and Frequency Control, Vol. 65, 2018, pp. 617-629.

[3] L. Iglesias. M.T. Boudjiet, I. Dufour, "Discrimination and concentration measurement of different binary gas mixtures with a simple resonator through viscosity and mass density measurements," Sensors and Actuators B, Vol. 285, 2019, pp:487-494, 2019.

[4] L. Iglesias, P. Shanmugam, S. Pena, J.F. Michaud, D. Alquier, L. Colin, D. Certon, I. Dufour, "CMUT enabled binary mixture gas sensing through time of flight measurement," The 16th International Workshop on Nanomechanical Sensors, 19-21 June 2019, Lausanne, Switzerland, 2 pages.

[5] L. Iglesias, P. Shanmugam, J.F. Michaud, D. Alquier, D. Certon, I. Dufour, "Cmut Time of Flight Gas Sensor By Phase Shift Measurement," $18^{\text {th }}$ International Meeting on Chemical Sensors IMCS 2020, Montreal, Canada, 10-14 May 2020. 3 pages. accepted 